\title{
Loss of contrast sensitivity in diabetic patients with LOCS II classified cataracts
}

Leo T Chylack Jr, Nita Padhye, Patricia M Khu, Caroline Wehner, John Wolfe, Daniel McCarthy, Bernard Rosner, Judith Friend

\begin{abstract}
Contrast sensitivity function (CSF) was assessed in a population of diabetics with moderate cataracts to determine if CSF testing provides more information about visual dysfunction than Snellen or Lotmar interferometric visual acuity. With the Lens Opacities Classification Systems Version II (LOCS II) of cataract classification it was possible to grade accurately the type and severity of cataract and nuclear brunescence. The presence of statistically significant relationships between increasing LOCS II classification (worsening cataract) and diminished function, even when the regression model was controlled for Snellen visual acuity, supports the thesis that CSF measurements do provide more information about cataract related visual loss than Snellen acuity alone. Statistically significant $(p \leq 0.05)$ relationships existed between different morphological types of cataract, nuclear colour, and CSF at specific frequencies. The frequencies affected differed with cataract type or nuclear colour, and with distance and near CSF.

(Br f Ophthalmol 1993; 77: 7-11)
\end{abstract}

For decades clinicians have noted the discrepancy between the extent of an age-related cataract and the severity of the visual disability measured using high contrast Snellen acuity charts which may not be sensitive to visual disability characterised by loss of contrast sensitivity function (CSF). To quantify low contrast visual disability, ophthalmologists recently have measured CSF; there are several commercial methods available for this purpose including the Vistech placards (Model No 6500$)^{1}$ or the PelliRobson charts. ${ }^{2}$ It is not clear if CSF testing provides more useful information about visual dysfunction than Snellen acuity alone. Moreover, it is not clear if one type of cataract affects CSF more than another type. Several investigators have reported changes in CSF with specific cataract types. For example, Skalka ${ }^{3}$ and Paulsson and Sjöstrand ${ }^{4}$ demonstrated loss of contrast sensitivity in posterior subcapsular cataract; Elliott and Gilchrist ${ }^{5}$ found that advanced cortical, nuclear, and posterior subcapsular cataract adversely affected CSF. Typically, loss of contrast sensitivity in patients with cataract has been reported to be greater at higher spatial frequencies, ${ }^{3-7}$ though some have reported effects at low frequencies in normal persons ${ }^{8}$ and diabetics.'

Recently, we and others have published descriptions and validation data for the Lens Opacities Classification Systems LOCS $\mathrm{I}^{1011}$ and
LOCS II. ${ }^{1213}$ With these highly reproducible systems, it is now possible to define cataract type and extent very accurately. This, in turn, permits us to define the effects of specific cataract types and degrees on specific visual functions. These validated systems of cataract classification now permit us to control for cataract type and severity in regression analyses of sources of abnormal CSF.

The purposes of this study were: (1) to determine the relationship between the extent and type of cataract and the severity of loss of near and distance contrast sensitivity in a population of diabetic patients whose cataracts have been classified with a valid system of cataract classification; and (2) to determine if Vistech CSF testing charts provide any more information than Snellen acuity alone in quantitative cataractrelated visual loss. To do so, we measured cataract severity using the LOCS II system, near and distance CSF at five spatial frequencies with the Vistech VCTS 6500 and 6000 charts, and visual acuity in a population of diabetic patients.

\section{Materials and methods}

PATIENT POPULATION

Data were collected from 88 eyes of 49 diabetic volunteers (19 males and 30 females) ranging in age from 32-75 (mean age 62.5). The patients were recruited for a study of the natural history of diabetic cataractogenesis from the Brigham and Women's Hospital, The Massachusetts Eye and Ear Infirmary, and The Joslin Diabetes Center, and met the following inclusion criteria: 21-75 years of age; Type I or II diabetes mellitus with stable diabetic control (that is, there was no change in the type of therapy for diabetes other than dosage adjustment). Diabetic control was assessed at baseline and at each visit by determination of $\mathrm{HbA}_{1} \mathrm{c}$; the mean $\mathrm{HbA}_{1} \mathrm{c}$ at baseline was $10.0 \%$ (range $6.6-15.9 \%$ ) which corresponds to fair to poor diabetic control. Other inclusion criteria were: early immature cataract; patient was unlikely to require cataract extraction within $2^{1 / 2}$ years; and the patient was willing to give informed consent. There were no pregnant or nursing women; no subjects with cataracts other than senile or diabetic (for example, steroid-induced, traumatic, etc); no eye infections within the past month; no patients with proliferative diabetic retinopathy or history of laser photocoagulation; no persons who had used therapeutic doses of systemic steroids for a period longer than 4 weeks, who took aspirin ( $>1300 \mathrm{mg} /$ day), or used a topical ophthalmic medication chronically; no persons who were on concomitant therapy with an investigational 
drug; no persons at risk of angle closure glaucoma; and no persons with severe debilitating disease.

\section{EXPERIMENTAL PROCEDURES AND EVALUATIONS}

Cataract classification using the Lens Opacities Classification System II (LOCS II)

LOCS II cataract classifications were derived from Neitz-CTR retroillumination, Topcon Scheimpflug, and Zeiss colour slit-lamp lens photographs taken on dilated eyes according to a standard protocol..$^{12}$ The grades used were consensus grades by LTC and DM. Consensus grades were arrived at as follows: each of the two graders graded each photograph independently. Then, the two graders discussed any discrepancy in grading and a grade that was acceptable to both graders was decided upon and used as the grade for that photograph. Cortical (C) opacities were graded from 0-5; posterior subcapsular cataracts (P) were graded from 0-4; nuclear opalescence (nuclear cataract, NO) from 0-4; and nuclear colour (brunescence, $\mathrm{NC}$ ) from $0-2 .{ }^{12}$

\section{Contrast sensitivity function (CSF)}

Distance CSF was tested monocularly at 10 feet with the best distance spectacle correction in place using the Vistech distance contrast sensitivity chart (VCTS 6500) with a constant illuminance of 30-70 foot Lamberts. The test stimuli were sinewave gratings of varying contrast at five spatial frequencies: $1.5 \mathrm{cpd}$ (cycles/degree), 3.0 cpd, $6.0 \mathrm{cpd}, 12.0 \mathrm{cpd}$, and $18.0 \mathrm{cpd}$. The test proceeded from higher to lower contrast and from lower to higher spatial frequency. At each spatial frequency, the target with the lowest contrast that was correctly identified before any preceding error was recorded as the contrast sensitivity for that frequency. Contrast sensitivity values, derived from the table provided in the Vistech manual, ${ }^{14}$ range from 3 to 260 and depend on the frequency. To obtain a normal distribution of contrast sensitivity measurements in the population, the logarithmic transform of 1 plus the $C S$ value was used for statistical analysis. Near CSF was tested similarly with the VCTS 6000 chart at 18 inches. The results of near CSF are analysed with respect to Snellen distance visual acuity (VA). While in principle it would have been desirable to use Jaeger near VA instead of Snellen distance VA, that was not possible since Jaeger scores were not available for all patients.

For statistical analyses, the responses to the five individual spatial frequencies tested were averaged into three groups: low frequency (1.5 and $3.0 \mathrm{cpd})$, middle frequency $(6.0 \mathrm{cpd})$, and high frequency $(12 \cdot 0$ and $18 \cdot 0 \mathrm{cpd})$.

\section{Best corrected visual acuity (VA)}

1 Snellen visual acuity (Snellen VA). Best corrected Snellen visual acuities were measured with a Projecto-Chart (American Optical) in a 20 foot lane. For statistical analyses, the Snellen acuity was converted to $\ln (1 /$ Snellen acuity).

2 Lotmar interferometric visual acuity (LIVA).
After measurement of Snellen VA and CSF, pupils were dilated and the Lotmar interference fringe acuitimeter ${ }^{15}$ attached to the Haag-Streit slit-lamp was used to assess the macular interference fringe acuity. Lotmar interferometric visual acuity (LI VA) was recorded as a decimal from $0-1$ (with $0 \cdot 1$ equivalent to $20 / 200$ Snellen acuity and 1.0 equivalent to 20/20 Snellen acuity). The end point was the smallest fringe for which the patient correctly indicated all four azimuthal directions (vertical, horizontal, and $45^{\circ}$ to right and left). For statistical analyses we used $\ln$ (1/LI VA).

3 Macular appearance. This was designated either visibly normal (0) or abnormal (1) as viewed with the direct ophthalmoscope. It was considered abnormal if retinal thickening or hard exudates were at or within $500 \mu \mathrm{m}$ of the centre of the macula.

The retinal status was designated normal if there were no extramacular signs of diabetic retinopathy: microaneurysms, retinal haemorrhages, exudates, venous beading, or proliferative retinopathy. If any of the above signs of diabetic retinopathy were seen, the retina was regarded as abnormal. Retinopathy was graded on the following coarse categorical scale: $1=$ normal; 2 =mild; 3 =moderate; $4=$ severe. There were no cases of proliferative retinopathy. The standardised methods of grading diabetic retinopathy were not available when this study began.

\section{DATA ANALYSIS}

A GLMIC, a multivariate, generalised least squares regression model with intraclass correlation $^{16}$ was used to analyse the data. For example, in this model, the effects of a specific type of cataract (for example, cortical) on low frequency CSF can be defined by controlling for Snellen visual acuity, age, and sex:

$$
\begin{aligned}
y_{i j}=\alpha+\beta_{1} x_{1 i j}+\beta_{2} x_{2 i j}+\beta_{3} x_{3 i j}+\beta_{4} x_{4 i j}+\beta_{5} x_{5 i}+\beta_{6} x_{6 i}+e_{i j} \\
i=\text { denotes patient } \\
j=1 \text { if right eye (OD) and } 2 \text { if left eye } \\
\quad(\mathrm{OS})
\end{aligned}
$$

where

$$
\begin{aligned}
y_{i j}= & \text { averaged contrast sensitivity score at } \\
& \text { low frequency for eye } j \text { of patient } i \\
x_{1 i j}= & \text { LOCS II cortical grade } \\
x_{2 i j}= & \ln (1 / \text { Snellen } \text { (best corrected) VA } \\
x_{3 i j}= & \text { retinal status }(1 \text { to } 4) \\
x_{4 i j}= & \text { macular status }(0=\text { normal; } \\
& 1=\text { abnormal }) \\
x_{5 i}= & \text { age in years } \\
x_{6 i}= & \text { sex }(1=\mathrm{m} ; 0=\mathrm{F}) \\
e_{i j}= & \text { error term assumed to be normal with } \\
& \text { mean }=0 \text { and variance }=\sigma^{2} .
\end{aligned}
$$

The correlation between $e_{1}$ and $e_{2}$ is $\varrho$ which represents the intraclass correlation between CSF for the right and left eyes after controlling for the covariates. This is similar to multiple linear regression except that the error terms are assumed to be correlated, and one estimates both the regression coefficient $B$ and the correlation parameter $\varrho$ in the same model using maximum likelihood methods. Similar models were run for the other cataract types (P, NO, and NC) and for 
Table 1 Distribution of cataract grades

\begin{tabular}{llllllll}
\hline & \multicolumn{7}{l}{ LOCS II grade } \\
\cline { 2 - 7 } LOCS II category & 0 & $\operatorname{tr}(0 \cdot 5)$ & 1 & 2 & 3 & 4 & 5 \\
\hline Cortical & $7(8 \%)$ & $13(15 \%)$ & $12(14 \%)$ & $30(34 \%)$ & $17(19 \%)$ & $4(5 \%)$ & $5(6 \%)$ \\
Posterior subcapsular & $72(82 \%)$ & na & $3(3 \%)$ & $6(7 \%)$ & $3(3 \%)$ & $4(5 \%)$ & na \\
Nuclear opalescence & $15(17 \%)$ & na & $51(58 \%)$ & $14(16 \%)$ & $8(9 \%)$ & na & na \\
Nuclear colour & $16(18 \%)$ & na & $28(32 \%)$ & $44(50 \%)$ & na & na & na \\
\hline
\end{tabular}

The number of cataracts for each LOCS II grade is presented for each class of cataract: cortical cataract $(C)$, posterior subcapsular cataract $(P)$, nuclear opalescence (NO), and nuclear colour (NC). $\mathrm{na}=$ not available, and refers to the fact that there are no LOCS II scores possible for these grades of na $=$ not available, and refers

Table 2 Significance of Spearman correlation coefficients ( $\mathrm{Q}$ between cataract type and nuclear colour

\begin{tabular}{lllll}
\hline & Cortical & $\begin{array}{l}\text { Posterior } \\
\text { subcapsular }\end{array}$ & $\begin{array}{l}\text { Nuclear } \\
\text { opalescence }\end{array}$ & $\begin{array}{l}\text { Nuclear } \\
\text { colour }\end{array}$ \\
\hline Cortical & 1.00 & $0 \cdot 150$ (NS) & $0 \cdot 287$ (NS) & $0 \cdot 104$ (NS) \\
Posterior subcapsular & - & 1.00 & $0.330(\mathrm{NS})$ & 0.080 (NS) \\
Nuclear opalescence & - & - & 1.00 & 0.575 \\
Nuclear colour & - & - & - & $\begin{array}{l}(0.0001) \\
1 \cdot 00\end{array}$ \\
\hline
\end{tabular}

The Spearman correlation coefficients between cataract types and nuclear colour are given, with the $p$ value in parentheses, for each possible relationship. The relationship is considered statistically significant and the $p$ value presented if $p \leq 0.05$. If $p \leq 0.05$, the relationship is considered NS (not significant). the grades of cataract or nuclear colour defined using LOCS II. All types of cataract and nuclear colour had adverse effects on Snellen visual acuity in this population.

Nuclear opalescence, posterior subcapsular cataract, and nuclear colour, but not cortical cataract, had adverse effects on LI VA.

It is, therefore, of obvious importance to control for both measures of visual acuity in a statistical model testing the relationship between LOCS II grade and CSF.

\section{DISTANCE AND NEAR CSF AND CATARACT OR}

NUCLEAR COLOUR

When the relationship between distance and near CSF and LOCS II cataract or nuclear colour is studied, there is a maximum contrast sensitivity at $3.0 \mathrm{cpd}$ and a minimum at $18.0 \mathrm{cpd}$ with cataract resulting in a drop in CS. (Figures 1A1D demonstrate this for distance CS. Near CS was similar; the data are not presented.) The statistical significance of the relationships is presented below and in Tables 4 and 5 .

all four cataract types considered together controlling for LI VA, age, and sex.

The results are expressed as regression coefficients (beta, B) indicating the direction and magnitude of the effects and $p$ values indicating the statistical significance of specific regression coefficients.

Spearman rank correlation coefficients were calculated to determine relations between grades of severity of different cataract types. ${ }^{17}$

\section{Results}

CATARACT FREQUENCY

The distribution of grades of cataracts in the population is given in Table 1 for $\mathrm{C}, \mathrm{P}, \mathrm{NO}$, and NC.

CORRELATION BETWEEN CATARACT TYPES

There are significant relationships between grades of nuclear opalescence and nuclear colour, but not between grades of other cataract types or nuclear colour (Table 2).

VISUAL ACUITY AND CATARACT OR NUCLEAR COLOUR

Table 3 illustrates the relationships between the Snellen and interferometric visual acuities and

Table 3 Correlation of cataract and nuclear colour and visual acuity

\begin{tabular}{llrlll}
\hline & \multicolumn{3}{l}{$\begin{array}{l}\text { Snellen visual } \\
\text { acuity }\end{array}$} & \multicolumn{3}{l}{$\begin{array}{l}\text { Lotmar visual } \\
\text { acuity }\end{array}$} \\
\cline { 2 - 3 } LOCS II cataract & Beta & $p$ & Beta & $p$ \\
\hline Cortical & $0 \cdot 105$ & 0.034 & $0 \cdot 027$ & NS \\
Posterior subcapsular & $\mathbf{0 . 2 6 7}$ & $<0.001$ & $0 \cdot 062$ & $\mathbf{0 . 0 3 8}$ \\
Nuclear colour & $\mathbf{0 \cdot 2 8 4}$ & $<\mathbf{0 . 0 0 1}$ & $\mathbf{0 \cdot 1 0 3}$ & $\mathbf{0 . 0 1 2}$ \\
Nuclear opalescence & $\mathbf{0 \cdot 1 6 8}$ & $\mathbf{0 . 0 4 0}$ & $\mathbf{0 \cdot 1 0 4}$ & $\mathbf{0 . 0 1 8}$ \\
\hline
\end{tabular}

The values represent four GLMIC analyses. The association is considered statistically significant and the $\mathrm{p}$ value is given in bold if $p \leq 0.05$. If $p \geq 0.05$, the relationship is considered NS (not significant)
STATISTICAL ANALYSES OF CSF AND CATARACT OR NUCLEAR COLOUR ASSOCIATIONS

GLMIC analysis of the association of cataract with averaged contrast sensitivity from three frequency levels: low ( 1.5 and $3.0 \mathrm{cpd})$, middle (6.0 cpd), and high $(12.0$ and $18.0 \mathrm{cpd})$ are presented in Tables 4 and 5. Two statistical models were run. One controlled for age, sex, retina status, macular status, and LI VA to detect changes in CSF owing to cataract, and one controlled for age, sex, retinal status, macular status, and Snellen VA to test whether CSF provides information beyond that available with Snellen VA testing.

Statistical model controlled for age, sex, retinal/macular function, and LIVA (Table 4)

Cortical cataract is associated with decreased distance CSF at all frequencies and decreased near CSF at middle and high frequencies $(\mathrm{p} \leq 0.05)$.

Posterior subcapsular cataract is associated with decreased distance and near CSF at all spatial frequencies ( $\mathrm{p} \leq 0.05)$.

Nuclear opalescence is associated with decreased distance and near CSF at all frequencies ( $\mathrm{p} \leq 0.05$ ). tance CSF at high frequencies $(p=0.039)$ and with decreased near CSF at all frequencies ranges $(\mathrm{p} \leq 0 \cdot 05)$.

Statistical model controlled for age, sex, retinal/macular function, and Snellen VA (Table 5) When the model is controlled for Snellen VA, age, sex, and retinal/macular status, increasingly extensive cortical opacification is associated with worsening distance CSF at middle and high spatial frequencies $(p \leq 0.05)$. The near CSF data indicate that worsening cortical cataract has a statistically significant effect only at the middle spatial frequency $(p \leq 0 \cdot 05)$.
Nuclear colour is associated with loss of dis- 
Table 4 Regression analysis of near and distant contrast sensitivity and LOCS II cataract classification controlled for Lotmar interferometric visual acuity

\begin{tabular}{|c|c|c|c|c|c|c|}
\hline \multirow{3}{*}{$\begin{array}{l}\text { LOCS II type of cataract } \\
\text { or nuclear colour }\end{array}$} & \multicolumn{6}{|c|}{ Spatial frequency } \\
\hline & \multicolumn{2}{|c|}{$\begin{array}{l}\text { Low } \\
(1.5 \text { and } 3.0 \text { cpd })\end{array}$} & \multicolumn{2}{|l|}{$\begin{array}{l}\text { Middle } \\
(6 \cdot 0 \mathrm{cpd})\end{array}$} & \multicolumn{2}{|c|}{$\begin{array}{l}\text { High } \\
(12.0 \text { and } 18.0 \mathrm{cpd})\end{array}$} \\
\hline & Beta & $p$ & Beta & $p$ & Beta & $p$ \\
\hline $\begin{array}{l}\text { Distance CSF } \\
\text { Cortical } \\
\text { Posterior subcapsular } \\
\text { Nuclear opalescence } \\
\text { Nuclear colour } \\
\text { Near CSF }\end{array}$ & $\begin{array}{l}-0.182 \\
-0.264 \\
-0.426 \\
-0.182\end{array}$ & $\begin{array}{l}0.01398 \\
0 \cdot 0017 \\
0 \cdot 0003 \\
0 \cdot 178\end{array}$ & $\begin{array}{l}-0.273 \\
-0.199 \\
-0.390 \\
-0.224\end{array}$ & $\begin{array}{l}0.0011 \\
0 \cdot 0481 \\
0 \cdot 0052 \\
0 \cdot 157\end{array}$ & $\begin{array}{l}-0.221 \\
-0.191 \\
-0.316 \\
-0.291\end{array}$ & $\begin{array}{l}0.0044 \\
0.0343 \\
0.0143 \\
0.0390\end{array}$ \\
\hline $\begin{array}{l}\text { Cortical } \\
\text { Posterior subcapsular } \\
\text { Nuclear opalescence } \\
\text { Nuclear colour }\end{array}$ & $\begin{array}{l}-0.114 \\
-0.300 \\
-0.363 \\
-0.289\end{array}$ & $\begin{array}{l}0.093 \\
0.0001 \\
0.0005 \\
0.0125\end{array}$ & $\begin{array}{l}-0.245 \\
-0.285 \\
-0.468 \\
-0.491\end{array}$ & $\begin{array}{l}0.0053 \\
0.0052 \\
0.0009 \\
0.0013\end{array}$ & $\begin{array}{l}-0.154 \\
-0.241 \\
-0.350 \\
-0.215\end{array}$ & $\begin{array}{l}0.0492 \\
0.0060 \\
0.0061 \\
0.0021\end{array}$ \\
\hline
\end{tabular}

The regression coefficient (beta) and statistical significance ( $p$ ) for the relationships between contrast sensitivity and severity of cataract or nuclear colour averaged for low $(1.5$ and $3.0 \mathrm{cpd})$, middle $(6.0$ $\mathrm{cpd})$, and high $(12.0$ and $18.0 \mathrm{cpd})$ spatial frequencies are presented. In addition to Lotmar interferometric visual acuity, results are controlled for age, sex, retinal status, and macular status.

There are no statistically significant $(\mathrm{p} \leq 0 \cdot 05)$ relationships between the severity of posterior subcapsular cataract and worsening distance or near CSF at any frequency.

There is an association between increasing nuclear opalescence and worsening distance CSF at low frequencies $(p \leq 0.05)$. There are no statistically significant associations between increasing $\mathrm{NO}$ and worsening near CSF.

Nuclear colour is statistically significantly associated with a loss of distance CSF at high frequencies $(p \leq 0.05)$ and there is a loss of near $\mathrm{CSF}$ at low, middle, and high frequencies which is statistically significant at low and middle frequencies ( $\mathrm{p} \leq 0.05)$.

Contrast sensitivity data were analysed as the logarithmic transform of one plus contrast value. As a result, the regression coefficients in Tables 4 and 5 are not directly applicable to predicting a linear change in CS with respect to LOCS II change. However, they can be used to predict a change over a specified range. For example, the mean CS at $6.0 \mathrm{cpd}$ for $\mathrm{NO}=0$ is 34.9 (see Figure 1). The regression coefficient for $\mathrm{NO}$ at $6.0 \mathrm{cpd}$ is -0.39 (see Table 4). For a unit increase in NO (that is, from 0 to 1 ), we would predict a decrease of 0.39 in the natural log of 1 plus the CS value; that is to say:

$\ln (1+34 \cdot 9)-0 \cdot 39=\ln (35 \cdot 9)-0 \cdot 39=3 \cdot 58-0 \cdot 39=3 \cdot 19$

Thus, the contrast sensitivity at $\mathrm{NO}=1$ is the antilog of $3 \cdot 19$ minus 1 , which is $23 \cdot 3$.

Table 5 Regression analysis of near and distant contrast sensitivity and LOCS II cataract classification controlled for Snellen visual acuity

\begin{tabular}{|c|c|c|c|c|c|c|}
\hline \multirow{3}{*}{$\begin{array}{l}\text { LOCS II type of cataract } \\
\text { or nuclear colour }\end{array}$} & \multicolumn{6}{|c|}{ Spatial frequency } \\
\hline & \multicolumn{2}{|c|}{$\begin{array}{l}\text { Low } \\
(1.5 \text { and } 3.0 \text { cpd })\end{array}$} & \multicolumn{2}{|l|}{$\begin{array}{l}\text { Middle } \\
(6 \cdot 0 \text { cpd })\end{array}$} & \multicolumn{2}{|c|}{$\begin{array}{l}\text { High } \\
(12.0 \text { and } 18.0 \mathrm{cpd})\end{array}$} \\
\hline & Beta & $p$ & Beta & $p$ & Beta & $p$ \\
\hline $\begin{array}{l}\text { Distance CSF } \\
\text { Cortical } \\
\text { Posterior subcapsular } \\
\text { Nuclear opalescence } \\
\text { Nuclear colour } \\
\text { Near } C S F\end{array}$ & $\begin{array}{l}-0.089 \\
-0.016 \\
-0.203 \\
-0.134\end{array}$ & $\begin{array}{l}0 \cdot 107 \\
0 \cdot 831 \\
0 \cdot 0299 \\
0 \cdot 172\end{array}$ & $\begin{array}{r}-0 \cdot 169 \\
0 \cdot 116 \\
-0 \cdot 144 \\
-0 \cdot 168\end{array}$ & $\begin{array}{l}0.0075 \\
0 \cdot 187 \\
0 \cdot 199 \\
0 \cdot 149\end{array}$ & $\begin{array}{l}-0.166 \\
-0.051 \\
-0.206 \\
-0.287\end{array}$ & $\begin{array}{l}0.0251 \\
0.598 \\
0 \cdot 103 \\
0.025\end{array}$ \\
\hline $\begin{array}{l}\text { Cortical } \\
\text { Posterior subcapsular } \\
\text { Nuclear opalescence } \\
\text { Nuclear colour }\end{array}$ & $\begin{array}{l}-0.025 \\
-0.035 \\
-0.130 \\
-0.209\end{array}$ & $\begin{array}{l}0.606 \\
0.579 \\
0.099 \\
0.0089\end{array}$ & $\begin{array}{l}-0.142 \\
-0.252 \\
-0.203 \\
-0.421\end{array}$ & $\begin{array}{l}0.0405 \\
0.781 \\
0.082 \\
0.0002\end{array}$ & $\begin{array}{l}-0.098 \\
-0.103 \\
-0.241 \\
-0.225\end{array}$ & $\begin{array}{l}0.188 \\
0.276 \\
0.056 \\
0.078\end{array}$ \\
\hline
\end{tabular}

The regression coefficient (beta) and statistical significance ( $p$ ) for the relationships between contrast sensitivity and severity of cataract or nuclear colour averaged for low $(1.5$ and $3.0 \mathrm{cpd})$, middle $(6.0$ cpd), and high (12.0 and $18.0 \mathrm{cpd})$ low, middle, and high spatial frequencies are presented. In addition to Snellen visual acuity, results are controlled for age, sex, retinal status, and macular addition

\section{Discussion}

In this population there is a correlation between different types of cataract and poorer Snellen or Lotmar visual acuities. Although the correlation with Snellen acuity is expected, the correlation with Lotmar interferometric visual acuity was less expected, since this test has been advocated as a measure of retinal acuity which is independent of medial opacities.

In this study we have attempted to isolate the effects of lens opacities on CSF from effects owing to retinal problems and to determine whether measurement of CSF adds any information beyond that obtained with high contrast visual acuity tests such as Snellen visual acuity. To that end we have looked for residual adverse effects of cataract on CSF after controlling the data for LI VA and Snellen VA and found that there are residual effects. In general, increasing severity of LOCS II-classified cataracts and nuclear colour adversely affects both distance and near CSF. However, not all of these adverse effects are statistically or clinically significant and the results after controlling for Snellen VA differ from those after controlling for LI VA. This suggests that CSF provides more information about vision than Snellen acuity alone, but that this additional information varies with different cataract types and degrees.

Using Spearman correlation coefficients we demonstrated that nuclear opalescence is signifcantly correlated with nuclear colour (Table 2, $\mathrm{p} \leq 0.0001$ ) in this population. Thus, the presence of nuclear opalescence will affect our results with nuclear colour. This makes it difficult to isolate specific effects of nuclear colour or nuclear opalescence on CSF in this small population.

However, the finding that worsening nuclear colour does appear adversely to affect CSF is potentially important and suggests nuclear colour may be considered an important contributor to loss of contrast sensitivity. This implies that clinical trials aimed at testing the efficacy of potential anticataract drugs must measure and control for nuclear colour when analysing their results. Failure to do this might lead to a failure to detect a beneficial effect on lens opacification (one that was obscured by increasing nuclear colour) or conversely to conclude incorrectly that the beneficial effect of a drug is due to its ability to decrease opacification (when in fact the effect may have been to reduce colour). However, to confirm these results and to separate the effects of nuclear colour and nuclear opalescence completely, it will be necessary to use a more sensitive method of lens colour analysis than LOCS II classification and one which can separate colour effects from nuclear opalescence effects. Fast spectral scanning colorimetry, a computerised method which provides continuous measures of lens colour parameters (for example, purity, dominant wavelength) independent of nuclear opalescence, ${ }^{18}$ will be used for these studies.

Howes et $a l^{9}$ studied contrast sensitivity in diabetics with different extents of cataract, but they did not use a validated, standardised cataract classification system to grade the type and severity of cataract. Rather, they graded the cataracts as mild (if there was no obstruction to the red fundal glow) and moderate (if there was 

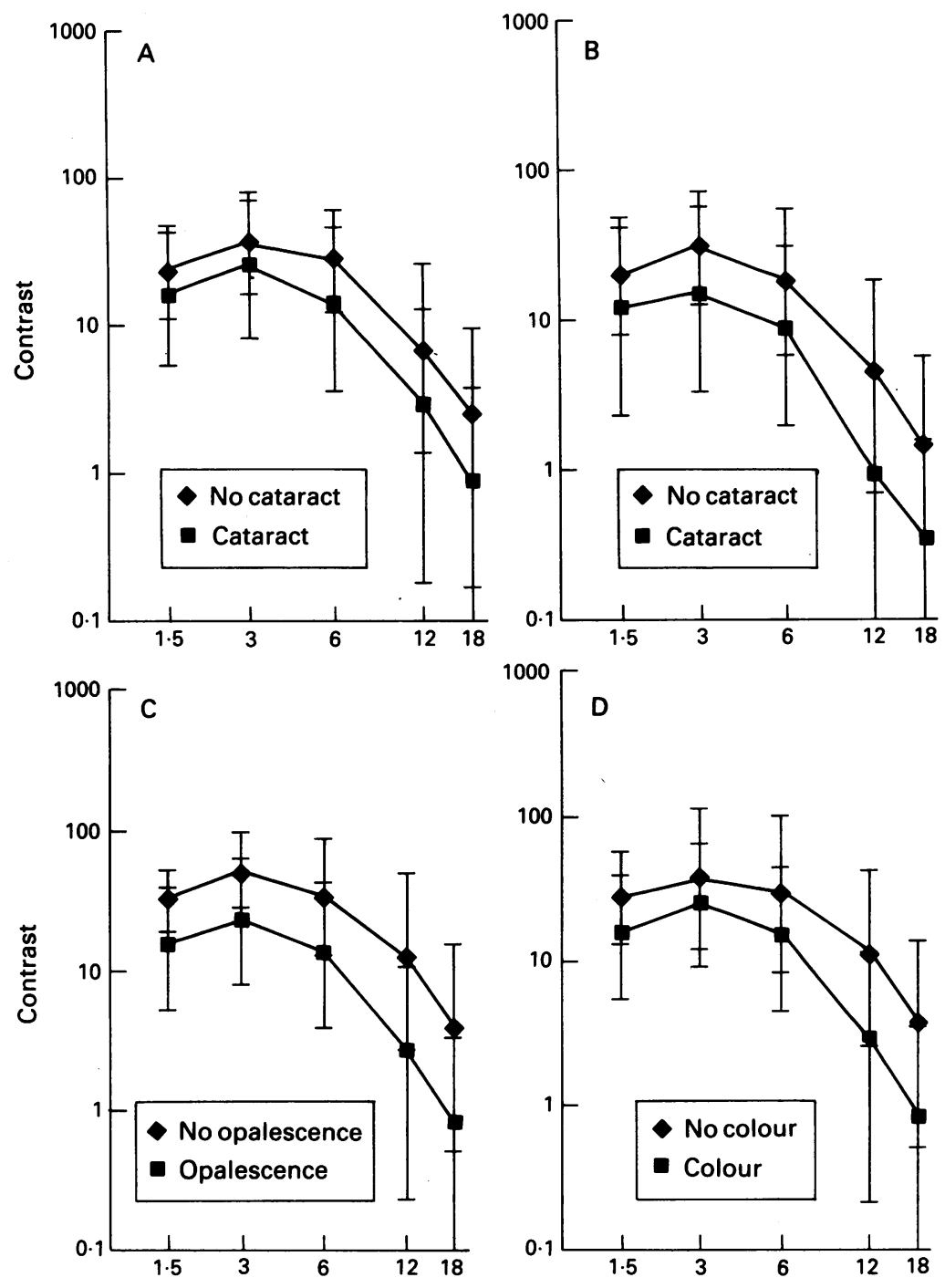

Frequency (cycles/degree)

Figure 1 Mean distance contrast sensitivity vs spatial frequency for LOCS II graded cataracts. The y axis is the mean contrast sensitivity adjusted for age, sex, and Snellen VA plotted on a log scale bracketed by the standard deviation. (A) Cortical cataract. Cortical cataract is divided into two classes: no cataract (grade 0 ) and cataract (grade $\geq$ tr). These are not pure cortical cataracts; they may also have $P, N O$, or NC components. (B) Posterior subcapsular cataract. Posterior subcapsular cataract is divided into two classes: no cataract (grade 0) and cataract (grade $\geq 0$ ). These are not pure posterior subcapsular cataracts; they may also have C, NO, or NC components. (C) Nuclear opalescence. Nuclear opalescence is divided into two classes: no opalescence (grade 0 ) and opalescence (grade $\geq 0$ ). These are not pure nuclear cataracts; they may also have $C, P$ or $N C$ components. (D) Nuclear colour. Nuclear colour is divided into two classes: no colour (grade 0) and colour (grade $\geq 0$ ). These cataracts may also have $C, P$, or NO components.

obstruction to the view of the retina with the fundus camera). Mild cataract was associated with loss at the low and medium spatial frequencies while moderate cataract suppressed sensitivity at all frequencies. They did not try to correlate nuclear colour with contrast sensitivity.

Two other studies have investigated the link between the type and extent of cataract, graded using a validated system of classification, and loss of contrast sensitivity at specific spatial frequencies. In both studies, frequency-specific changes were noted. Briefly, Chylack et al, ${ }^{8}$ using the

Vistech 6500 CSF method and LOCS II in a population of non-diabetic patients with early cataracts showed decreased CSF only at high frequency $(12.0$ to $18.0 \mathrm{cpd})$ for nuclear opalescence with no apparent effect for early posterior subcapsular or cortical cataract or nuclear colour. Elliott and Gilchrist ${ }^{5}$ found a CSF loss at 2, 4, and $10.6 \mathrm{cpd}$ for cortical and nuclear cataract and at $1,2,4$, and $10.6 \mathrm{cpd}$ for posterior subcapsular cataract defined using the Oxford system. ${ }^{1920}$ However, since in both those studies the populations were non-diabetics, the results may not be comparable with those reported here.

We are unable to generalise our results to all diabetics, because we did not derive this patient cohort from the general population, and the cohort is highly selected by the inclusion and exclusion criteria.

This project was supported by grants from Pfizer Central Research Inc, Groton, CT, The Brigham Surgical Group Foundation, and Inc, Groton, CT, The Brigham

Research to Prevent Blindness.
We would like to acknowledge the excellent administrative and We would like to acknowledge the excellent administrative and
technical support provided by Ms Margarett Baker, Mrs Ophelia White-Galindo, Ms Laura Bury, and Ms Ann Piccolomini.

1 Ginsburg A. A new contrast sensitivity vision test chart. $A m \mathcal{F}$ Optom Physiol Optics 1984; 61: 403-7.

2 Pelli DG, Robson JG, Wilkins AJ. The design of a new letter chart for measuring contrast sensitivity. Clin Vis Sci 1988; 2 187-99.

3 Skalka HW. Arden grating test in evaluating 'early' posterior subcapsular cataracts. South Med F 1981; 74: 1368-70.

4 Paulsson LE, Sjöstrand J. Contrast sensitivity in the presence of glare light. Theoretical concepts and preliminary clinical of glare light. Theoretical concepts and preliminary
studies. Invest Ophthalmol Vis Sci 1980; 19: 401-6.

5 Elliott DB, Gilchrist J. Contrast sensitivity changes with three types of cataract morphology: are these techniques necessary in a clinical evaluation of cataract? Ophthalmol Physiol Opt in a clinical eval

6 Koch DD. Glare and contrast sensitivity testing in cataractous patients. F Cataract Refract Surg 1989; 15: 158-64.

7 Hess R, Woo G. Vision through cataracts. Invest Ophthalmol Vis Sci 1978; 17: 428-35.

8 Chylack LT Jr, Jakubicz G, Rosner B, Khu P, Libman J, Wolfe JK, et al. Contrast sensitivity and visual acuity as functions of cataract type and extent (in preparation).

9 Howes SC, Caelli T, Mitchell P. Contrast sensitivity in diabetics with retinopathy and cataract. Aust $\mathcal{F}$ Ophthalmol diabetics with retin 1 173-8.

10 Chylack LT Jr, Leske MC, Sperduto R, Khu P, McCarthy D and The Lens Opacities Classification System Study Group. Lens opacities classification system. Arch Ophthalmol 1988; 106: $330-4$.

11 Leske MC, Chylack LT Jr, Sperduto R, Khu P, Wu S-Y, et al. Evaluation of a lens opacities classification system. Arch Ophthalmol 1988; 106: 327-9.

12 Chylack LT Jr, Leske MC, McCarthy D, Khu P, Kashiwagi $\mathrm{T}, \mathrm{Wu}$ S-Y, et al. Lens Opacities Classification System II. Arch Ophthalmol 1989; 107: 991-7.

13 Mariani G, Pasquini P, Tomba M, Bonacina M, Stazi MA, Rosmini F, et al. An independent evaluation of the Lens Opacities Classification System II (Lens Opacities ClassificaOpacities Classification System II (Lens Opacities
tion System II). Ophthalmology 1989; 96: 611-5.

14 Vistech VCTS 6500 Manual. Dayton, OH, 1987.

15 Bryant WR. The Haag-Streit Lotmar Visometer for determining macular potential prior to cataract surgery. $\mathcal{F} \mathrm{Am}$ Intraocular Implant Soc 1985; 11: 581 .

16 Rosner B. Multivariate methods in ophthalmology with application to other paired-data situations. Biometry $1984 ; 40$ 1025-35.

17 Conover WJ. Practical nonparametric statistics, 2nd ed. New York: Wiley, 1971: 254.

18 Chylack LT Jr, Wolfe JK, McCarthy D, Herzberg S, Khu PM, Padhye $\mathrm{N}$, et al. Cross-sectional and longitudinal correspondence between Lens Opacities Classification System II (subjective) and various objective measures of cataract and nuclear color. Invest Ophthalmol Vis Sci 1990; 31 (Suppl): 374.

19 Sparrow JM, Bron AJ, Brown NAP, Ayliffe W, Hill AR. The Oxford clinical cataract classification and grading system. Int Ophthalmol 1986; 9: 207-25.

20 Sparrow JM, Ayliffe W, Bron A, Brown NP, Hill AR. Interobserver and intra-observer variability of the Oxford clinical cataract classification and grading system. Int Ophthalmol 1988; 11: 151-7. 